\title{
NOMA: A Preventable "Scourge" of African Children
}

\author{
Kalu U.E. Ogbureke ${ }^{1,2, *}$ and Ezinne I. Ogbureke ${ }^{2}$ \\ ${ }^{I}$ Department of Oral Biology, ${ }^{2}$ Department of Oral Health and Diagnostic Sciences, School of Dentistry, \\ Medical College of Georgia, Augusta Georgia, U.S.A.
}

\begin{abstract}
Noma is a serious orofacial gangrene originating intraorally in the gingival-oral mucosa complex before spreading extraorally to produce a visibly destructive ulcer. Although cases of noma are now rarely reported in the developed countries, it is still prevalent among children in third world countries, notably in sub-Sahara Africa, where poverty, ignorance, malnutrition, and preventable childhood infections are still common. This review summarizes historical, epidemiological, management, and research updates on noma with suggestions for its prevention and ultimate global eradication. The global annual incidence remains high at about 140,000 cases, with a mortality rate exceeding $90 \%$ for untreated diseases. Where the patients survive, noma defects result in unsightly facial disfigurement, intense scarring, trismus, oral incompetence, and social alienation. Although the etiology has long been held to be infectious, a definitive causal role between microorganisms cited, and noma has been difficult to establish. The management of noma with active disease requires antibiotics followed by reconstructive surgery. Current research efforts are focused towards a comprehensive understanding of the epidemiology, and further elucidation of the microbiology and pathogenesis of noma.

Although a formidable public health challenge, noma can be prevented with a potential for subsequent global eradication. To achieve both desirable goals, detection of early disease is crucial because these early lesions respond to conventional antibiotic treatments when instituted side by side with nutritional rehabilitation, and obviates the necessity for extensive surgical reconstruction often indicated in late stage disease. The eradication of noma in the developed world in the mid $20^{\text {th }}$ century bears out the notion of a similar outcome following effective preventive strategies in Africa. A fundamental and necessary step towards attaining this goal is for the international community to adopt a perception of noma as an urgent global public health challenge. Research effort toward deciphering the microbiology, molecular events, and pathogenesis of noma also should intensify.
\end{abstract}

Keywords: Noma, Cancrum Oris, Sub-Sahara Africa, Acute Ulcerative Gingivitis, Preventable Disease, Surgical Management.

\section{BACKGROUND}

Noma (cancrum oris) is a debilitating gangrenous disease of the orofacial region. It occurs in several regions of the world, including the United States but with notable prevalence in sub-Sahara Africa [1,2]. Although noma can affect patients of any age group, infants and children are particularly susceptible [1]. Against a background of poor oral hygiene, long established common denominators to all noma patients are malnutrition, depressed immunity, and increased susceptibility to infections with normal oral commensal bacteria [3-7]. However, it is also true that not all patients, even with the complete set of predisposing conditions, develop noma. Indeed, because the majority of patients with these backgrounds never develop noma, it is reasonable to postulate that the biological factors enumerated above may only complement a stage set by other preexisting genetic and environmental conditions for the pathogenesis of noma.

Noma continues to be a significant cause of death among child patients in areas where it is currently endemic [3]. In the absence of timely therapeutic intervention, the mortality rate is estimated at about $70-90 \%[8,9]$. When not fatal,

*Address correspondence to this author at the Department of Oral Biology, School of Dentistry, Medical College of Georgia, $112015^{\text {th }}$ Street, Augusta, Georgia 30912, USA; Tel: 706 721-2526; Fax: 706 721-3392; E-mails: kogbureke@mail.mcg.edu; kogbureke@netscape.net noma leads to severe destruction of the mid-face structures, notably the lips, cheek, maxilla, mandible, nose, and orbital floor $[3,7,9]$. With the disfiguring sequel comes impaired self-nutrition, speech, and ultimately, social rejection [10]. Antibiotic regimens remain the mainstay of treatment for active disease. Plastic and reconstructive surgical procedures are subsequently employed for the repair of the substantial orofacial hard and soft tissue defects resulting from a completed natural course of the disease [10-12].

Africa not only maintains a disproportionate burden of noma cases currently, but this avoidable and preventable condition remains a visible scourge of African children [4, 13]. This review recaptures salient historical aspects of noma, and summarizes management and research updates on the etiology and pathogenesis of the disease. Strategies necessary for the prevention and ultimate eradication of noma are proffered.

\section{DISCUSSION}

\section{Historic and Epidemiological Profile of Noma}

The word "noma" is a derivative of the Greek word "nomein", which means, "to devour"; an obvious allusion to the rapidly destructive characteristic of the gangrene $[2,14]$. The first clinical description of the disease was said to be in 1595 by Carolus Battus, a Netherlands surgeon [15]. Subse- 
quently, A.L. Richter (a Berlin physician) in 1828 drew attention to the presence of noma throughout Europe over many centuries [16]. In his book, Richter also associated the disease with malnutrition and childhood infections such as measles. By the end of the $19^{\text {th }}$ century, noma had virtually disappeared from Western Europe as a result of improved nutrition and hygiene among poor people $[10,17]$. Although during the Second World War cases of noma were rife in Nazi concentration camps where victims died as a result of malnutrition $[18,19]$ treatment of active noma became possible with the discovery of penicillin but paradoxically after the disappearance of the disease from Europe.

Noma still remains the true "face of poverty" in less developed (and therefore impoverished) nations [20]. The 1994 report of the World Health Organization (WHO) characterized noma as a global health priority in response to reports from humanitarian organization indicating increases in the incidence of noma in various African countries [2, 21-24]. The report also coincided with an escalating economic crisis within the continent, combined with the advent of HIV/AIDS and the AIDS epidemic that followed, and an increasing number of armed conflicts. These conditions bear directly on the health and well being of children through overcrowded living conditions, deteriorating sanitation, and inadequate nutrition. In accord with its 1994 report, the WHO established a global campaign against noma as one of the initiatives emerging from that year's WHO Day celebration. It also initiated an action program by way of a joint project with the United States National Institute of Health (NIH) and the University of Maryland Baltimore, Maryland [2]. It stands to reason therefore that noma falls within the rubric of neglected infectious diseases within the domain of the dentist's practice.

Although epidemiological facts and figures relating to noma are at best fragmented and speculative, recent evidence points to an increasing incidence of noma, particularly in the poorer regions of Africa [4, 25, 26]. In 1998, the WHO made available the first estimates on the incidence and prevalence of noma with a worldwide annual incidence of 140,000 cases, and a prevalence of 770,000 in 1997 [9]. Estimates put the world number of children under the age of six years with noma in the order of several hundred thousand per year, including about 100,000 African children per year [3, 27]. The estimated incidence is between one and seven cases per 1000 population in African countries, and up to 12 cases per 1000 in the most affected communities [8, 13].

The main obstacle to the procurement of concrete global epidemiological data on noma is the limited or non-access of patients to healthcare centers and the attendant inadequacies of health record-keeping [8]. In addition, family members of patients as well as health personnel are often incapable of recognizing the condition. It is also not uncommon for noma to evolve so rapidly that death ensues before the patients can avail themselves of assistance from health facilities.

\section{Etiologic and Risk Factors for Noma}

Socioeconomic Factors. Poverty remains the single most important risk indicator for noma [13]. Other related factors include chronic malnutrition, poor environmental sanitation, unsafe water supply, close residential proximity to livestock, and increased exposure to viral and bacterial agents [3, 28]. As of 1999, sub-Sahara Africa harboured 38 of the world's 63 low-income nations, with a per capita annual income of $\$ 700$, and with $40 \%$ of its 500 million people subsisting on less than $\$ 1.00$ per day $[4,29]$. Thus, interplay of economic globalization with confounders such as war and drought constitutes the composite etiologic factor for noma [30, 31].

The global distribution pattern of noma mirrors the worldwide distribution of malnutrition, particularly that due to vitamin $A$ deficiency in children under the age of 5 years $[8,32]$; an observation that recapitulates that at the Nazi concentration camps where noma was rife in the $20^{\text {th }}$ century. In Nigeria, for example, most cases of noma become evident during the "dry season", an annual climatic variation coinciding with the "hungry months" due to food shortage [28, $29,33,34]$. The hungry months in Nigeria also coincide with the period of highest incidence of annual measles outbreaks [28, 29, 35, 36]. Anthropometric, biochemical, and clinical assessments of rural children in Sokoto Nigeria by Enwonwu et al. [3] showed widespread severe protein energy malnutrition (PEM) among noma patients when compared to their healthy but at-risk age-matched ethnic counterparts. The Sokoto village children studied by Enwonwu et al. [3] also exhibited marked deficiencies of retinol, ascorbate, zinc, and the essential amino acids.

Antecedent Oral and Systemic Conditions. Poor oral hygiene is a significant risk factor and follows as a natural sequel of ignorance and poverty rife in these communities [13, 34]. Poor oral hygiene is an essential predisposing condition to necrotizing ulcerative gingivitis (NUG) [13, 37]. NUG, generally considered a key predisposing factor (and not infrequently alluded to as a precursor lesion) to noma, is a socioeconomic disease that was seen almost exclusively among children in the developing countries following the end of the Second World War $[25,37,38]$. Clinically, NUG presents as a recurring gingival infection of complex etiology, characterized by necrosis of the interdental papillae, spontaneous bleeding, and pain (Fig. 1). Like noma, the pathogenesis of NUG is poorly understood although causative association with specific microorganism such as spirochetes, Prevottela intermedia, cytomegalovirus, Epstein-Barr, herpes simplex

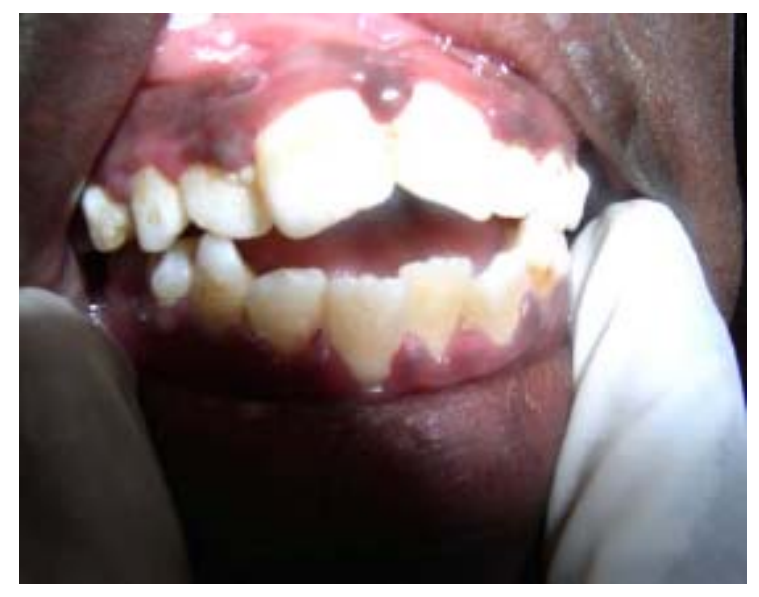

Fig. (1). Acute necrotizing ulcerative gingivitis (ANUG) showing characteristic punched-out crater-like ulcers. (see also Fig. 2 B). 

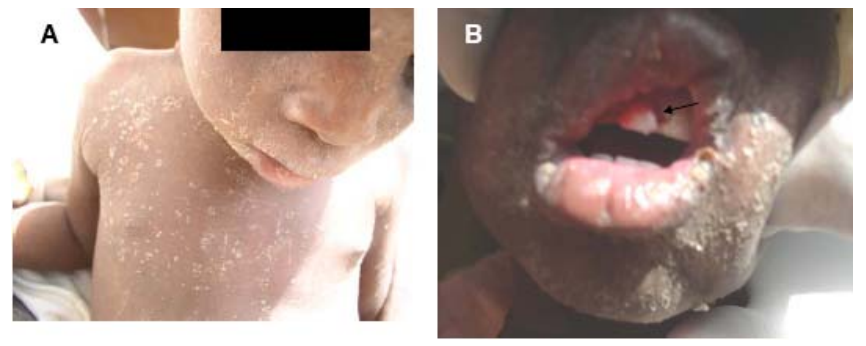

Fig. (2). Patients with measles $(A$ and $B)$. Measles ( $B$; arrow) usually antedate ANUG. (B; arrow).

viruses, and the measles virus is often cited [13, 25, 39-42]. Often patients may be under stress, immunosuppressed, or have endocrine dysfunction as additional predisposing conditions $[3,38,43,44]$.

Consistent with earlier reports [3, 45, 46] we have, over the years, observed that infection with measles (Fig. 2) most commonly antedates the development of noma in African children. In this respect other authors have cited interleukin12 (IL-12), an essential cytokine for the generation of cellmediated immunity, as being down-regulated in measles patients [3]. Records of other antecedent infections include malaria, tuberculosis, chicken pox, gastroenteritis, and bronchopneumonia [3, 47].

Microbiology of Noma. Although noma is presumed to be of infectious aetiology, elucidating the precise microbiological culprits remains somewhat of an enigma. The primary reason for this obscurity is obvious: the epicenter of noma development, the oral cavity, is inhabited by several hundred species of normal commensal bacteria [48-51]. A long held notion is that noma is caused by spirochetes and fusobacteria $[5,6,52]$. This notion partly stems from an extrapolation of the microbiological culprits of the presumed noma antecedent, NUG, which also includes spirochetes and fusobacteria, and partly because the levels of these organisms appear to be elevated in noma. However, a search of the English literature to date showed no reports of genotypic alterations from commensal to pathogenic among this group of organism in noma lesions. Furthermore, attempts to recapitulate the lesions of noma (or NUG) in animal models via inoculation of suspect oral organisms in the absence of predisposing conditions such as high plasma cortisol and depressed immunity have met with little success [2]. These findings challenge current etiologic concepts and continue to engender intense research effort in this direction. As a result, new theories are emerging regarding the pathogenesis of noma [53].

Another difficulty encountered results from a common speculation that differences in microbial population might exist between "early" and "advanced" lesions. Parameters for "early" and "advanced" noma lesions are yet to be precisely defined. In a broad sense however the early lesion refers to the reddish/purple-coloured indurations (Fig. 3) assumed to subsequently extend via ulceration and necrosis to adjoining hard and soft tissues of the orofacial region in the absence of timely treatment. On the other hand, the concept of advanced lesions alludes to the highly visible facial tissue destruction evidenced by the presence of exposed and/or sequestrated dead bone and soft tissue necrosis (Fig.

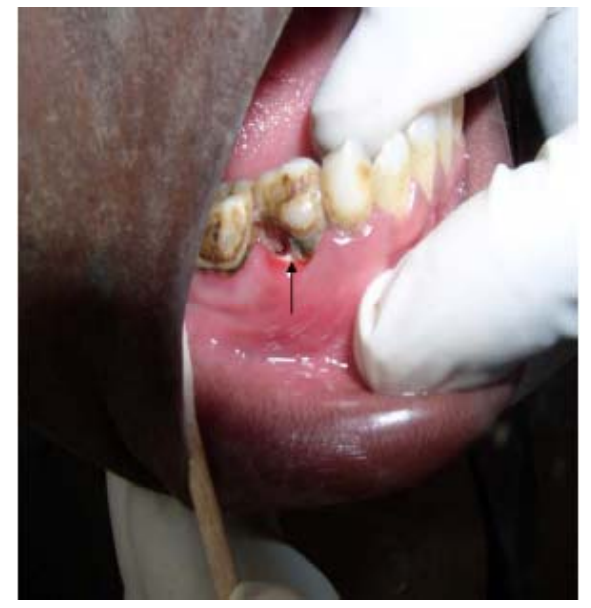

Fig. (3). Necrotic (Arrow ) erythematous ulcer still confined to the alveolus and gingiva. This may represent the so-called "early noma" lesion.

4) seen at later stages of the disease, or with rapidly progressing disease.

Nevertheless, recent reports suggest that noma is caused by a mixed infection of oral and extraoral opportunistic pathogens $[3,5,6,54]$ while incorporating the proposal that some noma cases may be the result of zoonotic infection with Fusobacterium necroforum. Using culture-independent molecular methods, Paster et al. [54] reported the detection of 67 bacterial species or phylotypes in advanced noma lesion of four Nigerian patients. Of these, phylotytpes that were unique to noma infections included those in the genera Eubacterium, Flavobacterium, Kocuria, Microbacterium, Porphyromonas, Streptococcus (salivarius), Sphingomonas, and Treponema. Twenty five species had not yet been grown in vitro, 19 phylotypes, including Propionibacterium acne, Staphylococcus species, and the opportunistic pathogens Stenotrophomonas maltophilia and Ochrobacterum antrophi were found in samples from one of the four patients. The authors suggested that the presence in advanced noma lesions of organisms not normally associated with the oral cavity may be due to contamination from the extraoral environment [54]. It however remains to be seen whether the microbial constituent of "early" lesions differs remarkably from that of advanced lesions.

\section{Current Management Approaches}

The consequences of noma relate to functional and esthetic problems. The acute and fulminating early stages of the disease indicate need for antibiotic treatment, while the chronic and disfiguring late stage requires surgical intervention: plastic and reconstructive surgeries designed to suit individual cases.

Medical Management: During the acute stage, treatment strategies aim to improve the overall health status of patients. This includes nutritional, correction of ionic and acid-base imbalances, administration of vitamins, and the administration of broad spectrum antibiotics to control infection [2]. In our cumulative experiences spanning over two decades at both the Maxillofacial Unit of the Ahmadu-Bello University Hospital, Kaduna (KUEO) and the Noma Children Hospital 


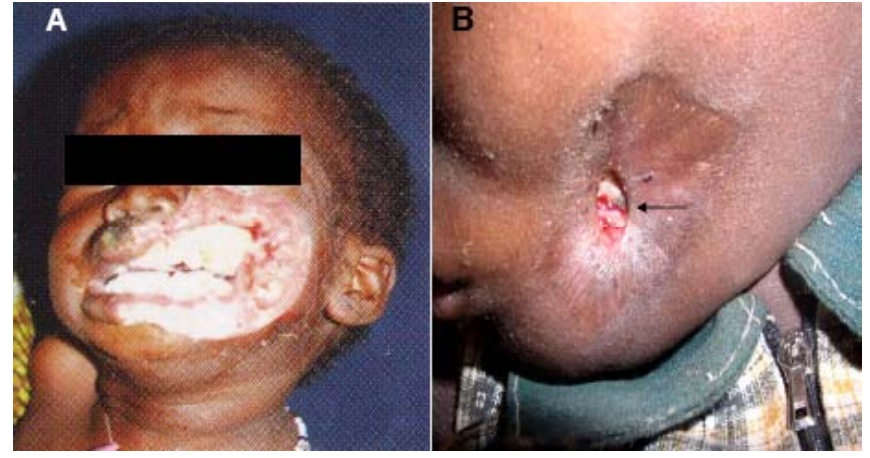

Fig. (4). Advanced noma lesions. A. Rapidly destructive and fulminating disease requiring lengthy antibiotic treatment prior to surgery. $\boldsymbol{B}$. Arrested advanced disease requiring short course of antibiotics before surgical reconstruction (arrow indicates sequestrum formation ( $\mathbf{4 A}$ is adapted from Noma Project, Courtesy of Noma Children Hospital, Sokoto, Nigeria).

Sokoto, Nigeria, antibiotics of the penicillin group with established potency in bone infections in combination with metronidazole were found to be consistently useful in arresting the fulminating acute phase of noma. Overall, the "goldstandard" remains that antibiotics administered at the acute phase must be sufficiently broad to cover the spectrum of aerobic and anaerobic organisms inhabiting the periodontium and oropharynx [2]. Improved oral hygiene instructions and strategy also must accompany early phase treatment.

Surgical Reconstruction: In the African settings where noma is overwhelmingly prevalent, there is also a shortage of qualified surgical teams to treat the number of patients requiring reconstruction $[2,25]$. In some of these centers, such as the Noma Children's Hospital in Sokoto, Nigeria, the local teams of surgeons and nurses are periodically supplemented by a volunteer team of expert representatives of humanitarian projects based in the developed countries [55].

The timing of surgical intervention in the management of noma is critical. All forms of invasive surgery in the vicinity of an acute phase lesion are discouraged because of the potential for such intervention to accelerate the destructive evolution of the disease. However, as soon as the acute phase is visibly contained, usually evidenced by clear fibrotic demarcation at the normal tissue-lesion interface (see Fig. 4) the design of surgical reconstruction should commence. Simultaneously, pre-surgical oral physiotherapy to relieve the trismus resulting from the fibrous strictures and ankylosis thereby enhancing intraoral access during surgery should also commence. In Nigerian centers, for example, graduated acrylic mouth screws are designed and fabricated, and these are employed to relieve trismus and enhance mouth opening. Physiotherapy continues postsurgical until acceptable or normal mouth opening is achieved.

Over the years, the surgical corrections of noma deformities have proved to be daunting because each new case appears to present a unique composite of reconstructive challenges. There is therefore no standard surgical approach common to all noma cases. Nevertheless, certain ground rules for surgical treatment of noma appears to exist, and include the postponement of treatment of lesions less than one-year-old (except where the sequelae created an urgent indication to improve nutritional intake), and the debridement of the lesion to avoid secondary infection [2]. Routine presurgical clinical investigations, including full blood count and differentials, chest, skull and, when feasible, full mouth radiological examinations must be carried out and documented. Skull radiographs that usually include temporomandibular joint (TMJ) views reveal the extent of bony ankylosis and trismus present in a particular patient [11, 56-58]. Various profiles of presurgical photographs are also documented, and subsequently used side-by-side with postsurgical photographs and other clinical parameters to assess treatment outcome.

Surgery, which is invariably under general anesthesia, sometimes presents peculiar anesthetic technique challenges and risks. For example, because most noma patients with significant loss of orofacial tissues and scarring develop limited mouth opening, intubation for general anesthesia is sometimes challenging. Before the advent of fibreoptic technology [59], intubation for anesthesia of noma patients preparatory for surgery presented significant risks and challenges, often compounded by the shortage of experienced nursing staff at centers located in the noma "hot spots" in Africa. It was therefore not uncommon for patients who electively present for the repair of their defects for social reasons, to die from anaesthetic complications during or after surgery.

Generally, the surgical designs involve the raising and transposition of local and distant soft tissue flaps, depending on the extent of tissue loss (see Fig. 4). In cases of considerable loss of facial or jaw bone, bone grafting may be considered in the sequence of reconstructive design. While a discussion of the technical details for each of the reconstructive designs advocated by various practitioners, together with their philosophies, is beyond the scope of this review, references to these details are cited in the text. Nevertheless, the three fundamental principles underlying every good surgical reconstruction design for noma repair are summarized. First, due to the substantial tissue loss characteristics of most noma defects, designs must account for adequate vascular supply capable of sustaining flap viability $[54,60]$. Therefore, both locoregional and pedicled flaps must maintain adequate distance from pathological tissues. Second, designs must aim for optimal length pedicles capable of anastomoses with local vessels in the area of repair [54, 59]. Third, an inner lining of the flap is required to prevent re-scarring and consequent functional impairment [61]. The deltopectoral, pedicled latissimus dorsi, pedicled radial forearm, and various designs of forehead flaps are routinely employed to close noma defects and provide outer lining [55]. Split-thickness skin grafts are commonly used to provide inner linings.

The deltopectoral flap has been used as both outer and inner linings with satisfactory results, and remains the most versatile flap for the reconstruction of facial defects [57, 62, 63]. The advantage of the deltopectoral flap lies in the relative simplicity of its design, minimal blood loss during surgery, and the viability of the flap after surgery [62, 63]. The various forehead flap designs are also simple. However, a main criticism of the forehead flaps is that they often result in unsightly appearance of the donor site. 
The various myocutaneous flaps mentioned above are intricate and should be employed only by practitioners with the appropriate experience and where adequate postoperative care is available because of the associated longer morbidity. Nath and Jovic $[62,63]$ advocate that myocutaneous flaps be sparingly used, if at all, in children. However, it would appear that for some considerably large and sophisticated defects myocutaneous flaps would remain the only viable reconstructive option. The Abbe-Estlander, nasolabial, and temporoauricular (Washio type) are local flaps that produce excellent results in small to moderate defects involving the upper lip, paranasal, and nasal areas [61]. Closure of oronasal fistulas can be achieved with the aid of tongue flaps [11]. Overall, because of the complexity of most noma defects, single surgical procedures are not always feasible, and most cases require revision surgeries to correct residual undesired functional and esthetic outcome of initial treatment.

\section{Research Update}

Prior to designating noma as one of the five global priorities for study by a joint initiative between NIH/NIDCR and WHO/ORH in the early 1990s, studies were carried out with less coordination amongst groups in the forefront of noma research. Following the characterization of noma as a major health problem requiring integrated international resources and expertise, the Federation Dentaire International (FDI) and the WHO Joint Working Group in 1992 launched the International Action Network Against Noma in 1994 [4]. This on-going initiative prompted studies that are now more coordinated with the ultimate goal of preventing and eradicating noma. It is hoped that this goal will be attained through studies elucidating more clearly the epidemiology of noma and its etiopathogenesis. In this regard, of course, the main battle-ground remains the developing countries of subSahara Africa.

A combined team of researchers from the Dental School of the University of Maryland, Forsyth Institute Boston, the Nigerian Institute of Medical Research Lagos, and the University of Lagos, School of Dentistry has been investigating the microbiological etiology of noma, as well as the immune and nutritional statutes of noma patients in Sokoto, Nigeria over the past decade.

\section{SUMMARY}

Although a formidable public health challenge, noma is both preventable and amenable to eradication. Detection of early lesions is crucial to an overall preventative goal because these early lesions respond to conventional antibiotic treatments when instituted side by side with nutritional rehabilitation, thereby obviating the late stage and potentially lethal gangrenes. The concept of "think globally act locally" [31] is clearly germane to the goal of eradicating noma in Africa and, by implication, globally. A fundamental and necessary step towards attaining this goal is for the international community to adopt a perception of noma as an urgent global public health challenge. This challenge must then be confronted by international agencies and research-sponsoring organization by addressing the various local logistical obstacles, increasing financial support for on-going research activities, and training local research scientists and mentors for noma centers in Africa.

\section{ACKNOWLEDGMENT}

KUEO's participation in the noma research project in conjunction with the Forsyth Institute, Boston was supported by the Division of Intramural Research, National Institute of Dental and Craniofacial Research, National Institute of Dental and Craniofacial Research, National Institutes of Health, Department of Health and Human Services, Bethesda, MD, U.S.A.

\section{REFERENCES}

[1] Enwonwu CO, Falkler WA, Idigbe EO. Oro-facial gangrene (noma/cancrum oris): pathogenetic mechanisms. Crit Rev Oral Biol Med 2000; 11:159-71.

[2] Baratti-Mayer D, Pittet B, Montandon D, et al., Geneva study group on noma. noma: an "infectious" disease of unknown aetiology. Lancet Infect Dis 2003; 3: 419-31.

[3] Enwonwu CO, Falkler WA Jr, Idigbe EO, Afolabi BM, Ibrahim M, Onwujekwe D. Pathogenesis of cancrum oris (noma): confounding interactions of malnutrition with infection. Am J Trop Med Hyg 1999; 60: 223-32.

[4] Idigbe EO, Enwonwu CO, Falkler WA, Ibrahim MM, Onwujekwe D, Afolabi BM. Living conditions of children at risk for noma: Nigerian experience. Oral Dis 1999; 5: 156-62.

[5] Falkler WA Jr, Enwonwu CO, Idigbe EO. Microbiological understandings and mysteries of noma (cancrum oris). Oral Dis 1999; 5: 150-55.

[6] Falkler WA, Enwonwu CO, Ewell AJ, Idigbe EO. Isolation of fusobacteria from the oral cavities of malnourished nigerian children living in agricultural and herding villages. Oral Dis 2000 6: 103-5.

[7] Obiechina AE, Arotiba JT, Fasola AO. Cancrum oris (noma): level of education and occupation of parents of affected children in Nigeria. Odontostomat Trop 2000; 23:11-14.

[8] Barmes DE, Enwonwu CO, Leclercq MH, Bourgeois D, Falkler WA. The need for action against oro-facial gangrene (noma). Trop Med Int Health 1997; 2: 1111-4.

[9] Bourgeois DM, Leclercq MH. The world health organization initiative on noma. Oral Dis 1999; 5: 172-4.

[10] Marck KW, de Bruijn HP. Surgical treatment of noma. Oral Dis 1999; 5: 167-71.

[11] Adekeye EO, Ord RA. Cancrum Oris: principles of management of reconstructive surgery. J Maxillofacial Surg 1983; 1: 160-70.

[12] Adolph HP, Yugueros P, Woods JE. Noma: a review. Ann Plast Surg 1996; 37: 657-68.

[13] Enwonwu CO. Noma: a neglected scourge of children in subSahara Africa. WHO Bull 1995; 73: 541-5.

[14] Marck KW. Cancrum oris and noma: some etymological and historical remarks. Br J Plast Surg 2003; 56: 524-7.

[15] Battus C. Handboeck der chirurgijen. Dordrecht: Abraham ende Isaak Canin 1595.

[16] Ritcher AL. Der Wasserkrebs der Kinder. Berlin: TFC Enslin, 1828.

[17] Fieger A, Marck KW, Busch R, Schmidt A. An estimation of the incidence of noma in north-west Nigeria. Trop Med Int Health 2003; 8: 402-7.

[18] Dawson J. Cancrum oris. Br Dent J 1945; 79: 151-7.

[19] Adelsberger L. Medical observations in auschwitz concentration camp. Lancet 1946; 1: 317-9.

[20] Marck KW. A history of noma, the "Face of Poverty. Plast Reconstr Surg 2003; 111: 1702-7.

[21] World Health Organization. A disease such as noma should not exist. noma contact. WHO publications October 1997; pp. 1-2.

[22] World Health Organization. Noma: a vicious and deadly disease. Noma Contact WHO 1997; p.2.

[23] World Health Organization. Delphi expert consultation. is noma today a public health problem? WHO/MMC/NOMA/98.1. WHO; Geneva, Switzerland 1998.

[24] World Health Organization. World health report, WHO, Geneva, Switzerland 1998.

[25] Sheiham A. An epidemiological survey of acute ulcerative gingivitis in Nigerians. Arch Oral Biol 1966; 11: 937-42. 
[26] Bourgeois DM, Diallo B, Frieh C, Leclercq MH. Epidemiology of the incidence of oro-facial noma: a study of cases in Dakar, Senegal, 1981-1993. Am J Trop Med Hyg 1999; 61: 909-13.

[27] World Health Organization Homepage. Noma, the face of poverty. WHO 2003; Available from: www.who.int/noma/noma_facepoverty.htm

[28] Tempest MN. Cancrum oris. Br J Surg 1966; 53: 1071-4.

[29] Enwonwu CO, Falkler Jr WA, Idigbe EO, Savage KO. Noma (cancrum oris): questions and answers. Oral Dis 1999; 5: 144-9.

[30] Ndaiye FC, Bourgeois D, Leclercq MH, et al. Noma: public health problem in senegal and epidemiological surveillance. Oral Dis 1999; 5: 163-6.

[31] Hobdell MH. Economic globalization and oral health. Oral Dis 2001; 7: 137-43

[32] DeOnis M, Monteiro C, Akre J, et al. The worldwide magnitude of protein-energy malnutrition: an overview from the WHO global database on child growth. WHO Bull 1993; 71: 703-12

[33] Jelliffe DB. Infective gangrene of the mouth (cancrum oris). Pediatrics 1952; 9: 544-50.

[34] Enwonwu CO. Epidemiological and biochemical studies of necrotizing ulcerative gingivitis and noma (cancrum oris) in Nigerian children. Arch Oral Biol 1972; 17: 1357-71.

[35] Morely D. Severe measles in the tropics I. Br Med J 1969; 1: 297300

[36] Morely D. Severe measles in the tropics II. Br Med J 1969; 1: 3635 .

[37] Osuji OO. Necrotizing ulcerative gingivitis and cancrum oris (noma) in Ibadan, Nigeria. J Periodontol 1990; 61: 769-72.

[38] Taiwo JO. Oral hygiene status and necrotizing ulcerative gingivitis in Nigerian children. J Periodontol 1993; 64: 1071-4.

[39] Listgarten MA, Socransky SS. Ultrastructural characteristics of a spirochete in the lesion of acute necrotizing ulcerative gingivostomatitis (vincent's infection). Arch Oral Biol 1964; 16:95-6.

[40] Sabiston CB Jr. A review and proposal for the etiology of acute necrotizing gingivitis. J Clin Periodontol 1986; 13: 727-34.

[41] Contreras A, Falkler WA Jr, Enwonwu CO, et al. Human herpesviridae in acute necrotizing ulcerative gingivitis in children in Nigeria. Oral Microbiol Immunol 1997; 12: 259-65.

[42] Emslie RD. Cancrum oris. Dent Pract Dent Rec 1963; 13: 481-95.

[43] Melnick SL, Roseman JM, Engel D, Cogen RB. Epidemiology of acute necrotizing ulcerative gingivitis. Epidemiol Rev 1988; 10: 191-211.

[44] Melnick SL, Alvarez JO, Navia JM, Cogen RB, Roseman JM. A case-control study of plasma ascorbate and acute necrotizing ulcerative gingivitis. J Dent Res 1988; 67: 855-60.

[45] Phillips RS, Enwonwu CO, Okolo S, Hassan A. Metabolic effects of acute measles in chronically malnourished Nigerian children. J Nutr Biochem 2004; 15: 281-8.
[46] Hussey G. Measles. In: Semba RD, Bloem MW, Eds. nutrition and health in developing countries. Totowa, NJ: Humana Press 2001; p. $163-76$

[47] Enwonwu CO, Phillips RS, Ferrell CD. Temporal relationship between the occurrence of fresh noma and the timing of linear growth retardation in Nigerian children. Trop Med Int Health 2005; 10: $65-73$.

[48] Dewhirst FE, Tamer MA, Ericson RE, et al. The diversity of periodontal spirochetes by $16 \mathrm{~S}$ rRNA analysis. Oral Microbiol Immunol 2000; 15: 196-202.

[49] Paster BJ, Boches SK, Galvin JL, et al. Bacterial diversity in human subgingival plaque. J Bacteriol 2001; 183: 3770-83.

[50] Kazor CE, Mitchell PM, Lee AM, et al. Diversity of bacterial populations on the tongue dorsa of patients with halitosis and healthy patients. J Clin Microbiol 2003; 41: 558-63

[51] Uohara GI, Knapp MJ. Oral fusospirochetosis and associated lesions. Oral Surg Oral Med Oral Pathol 1967; 24: 113-23.

[52] Horning GM. Necotizing gingivostomatitis: NUG to noma. Compend Contin Educ Dent 1996; 17: 951-4.

[53] Enwonwu CO. Noma--the ulcer of extreme poverty. N Engl J Med 2006; 354: 221-4.

[54] Paster BJ, Falkler WA Jr, Enwonwu CO, et al. Prevalent bacterial species and novel phylotypes in advanced noma lesions. J Clin $\mathrm{Mi}-$ crobiol 2002; 40: 2187-91.

[55] Giessler GA, Schmidt AB. Noma: experiences with a microvascular approach under west African conditions. Plast Reconstr Surg 2003; 112: 947-54

[56] Adekeye EO. Ankylosis of the mandible: analysis of 76 cases. J Oral Maxillofac Surg 1983; 41: 442-9.

[57] Adams-Ray WE, James JH. Cancrum oris: functional and cosmetic reconstruction in patients with ankylosis of the jaws. Br J Plast Surg 1992; 45: 193-8.

[58] Oluwasanmi JO, Lagundoye SB, Akinyemi OO. Ankylosis of the mandible from cancrum oris. Plast Reconstr Surg 1976; 57: 342-50.

[59] Tassonyi E, Lehmann C, Gunning K, Coquoz E, Montandon D. Fiberoptically guided intubation in children with gangrenous stomatitis (noma). Anesthesiology 1990; 73: 348-9.

[60] Kuhnel TS, Dammer R, Dunzl B, Beule AG, Strutz J. New split scar cheek flap in reconstruction of noma sequelae. Br J Plast Surg 2003; 56: 528-33.

[61] Nath S, Jovic G. Total loss of upper and lower lips: challenges in reconstruction. Br J Oral Maxillofac Surg 1998; 36: 460-1.

[62] Nath S, Jovic G. Cancrum oris: management, incidence, and implications of human immunodeficiency virus in Zambia. Plast Reconstr Surg 1998; 102: 350-7.

[63] Montandon D, Lehmann C, Chami N. The surgical treatment of noma. Plast Reconstr Surg 1991; 87: 76-86.

Received: November 23, 2009

(c) Ogbureke and Ogbureke; Licensee Bentham Open.

This is an open access article licensed under the terms of the Creative Commons Attribution Non-Commercial License (http://creativecommons.org/licenses/by-nc/3.0/) which permits unrestricted, non-commercial use, distribution and reproduction in any medium, provided the work is properly cited. 